\title{
Respostas fisiológicas de plantas de orégano (Origanum vulgare L.) cultivadas sob malhas coloridas e fertilizantes orgânicos
}

\section{Physiological responses of oregano plants (Origanum vulgare L.) cultivated under colored meshes and with organic fertilizers}

VANUZE COSTA DE OLIVEIRA ${ }^{1,4}$

ANACLETO RANULFO DOS SANTOS ${ }^{2}$

GIRLENE SANTOS DE SOUZA²

RICARDO MIRANDA DOS SANTOS ${ }^{3}$

Determinação de trocas gasosas em plantas de orégano.

Foto: V. Costa de Oliveira

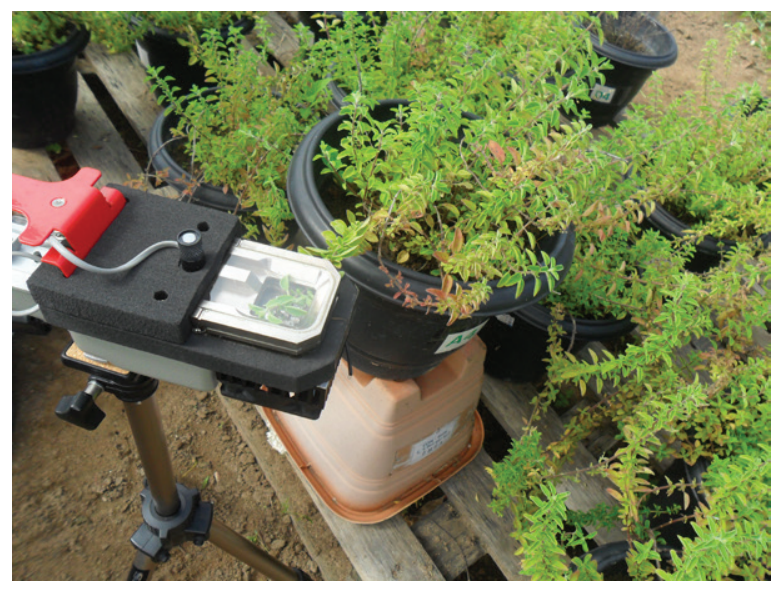

\section{RESUMO}

Este estudo objetivou avaliar índices de trocas gasosas e o crescimento de plantas de orégano cultivadas em ambientes de luz modificados com o uso de malhas coloridas e adubação orgânica. Foram utilizadas plantas de orégano com ciclo de 90 dias, obtidas por meio de estaquia convencional. Adotou-se o DIC, com seis repetições, em fatorial $3 \times 4$ (dois adubos orgânicos acrescido de testemunha, e quatro ambientes de luz modificada com o uso de malhas coloridas nas cores azul, cinza e vermelha, mais testemunha). As plantas de orégano cultivadas sob malha azul e adubadas com esterco bovino apresentaram maior número de folhas; as malhas coloridas proporcionaram maior comprimento de haste e maior produção de massa seca; as plantas crescidas a pleno sol apresentaram maiores valores para as trocas gasosas. Conclui-se que os ambientes de luz modificada e adubação orgânica contribuem para a redução de trocas gasosas e favorecem o crescimento do orégano.

Palavras chave adicionais: qualidade de luz, taxa fotossintética,
condutância estomática, massa seca de plantas.

Departamento de Ciência do Solo (DCS), Universidade Federal de Lavras (UFLA), Lavras-MG (Brasil). ORCID Costa de Oliveira, V.: 0000-0001-8979-5484

2 Centro de Ciências Agrárias, Ambientais e Biológicas (CCAAB), Universidade Federal do Recôncavo da Bahia (UFRB), Cruz das Almas-BA (Brasil). ORCID Ranulfo dos Santos, A.: 0000-0003-4629-3948; ORCID Santos de Souza, G.: 0000-0003-1526-7966

3 Departamento de Solos (DPS), Universidade Federal de Viçosa (UFV), Viçosa-MG (Brasil). ORCID Miranda dos Santos, R.: 0000-0002-2955-8011

4 Autor para correspondência.vanuze.costa@gmail.com 


\section{ABSTRACT}

This study aimed to assess the rates of gas exchange and growth of oregano plants grown in light environments modified with the use of colored screens and organic fertilizer. Oregano plants with a 90-day cycle were used, obtained with conventional cutting. A completely randomized design with six replications was employed in a $3 \times 4$ factorial scheme (two organic fertilizers plus control, and four light environments modified using screens with the colors blue, gray and red plus the control). The oregano plants grown under the blue mesh and fertilized with cattle manure showed a higher number of leaves; the colored screens provided greater stem length and a higher production dry matter; plants grown in full sun showed higher values for gas exchange. It is concluded that the modified light environments and organic fertilizer contributed to the reduction of the gas exchange and favored oregano growth.

Additional key words: light quality, photosynthetic rate, stomatal conductance, plant dry mass.

Data de recepção: 16-01-2017 Aprovado para publicação: 30-09-2017

$\longrightarrow$

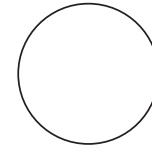

O consumo e uso de plantas condimentares, aromáticas e medicinais nos últimos anos tem aumentado no mundo o que parece ser evidente no Brasil, o que tem ocasionado o aumento no cultivos destes vegetais. No Brasil, o orégano (Origanum vulgare L.) está entre as mais utilizadas, em especial para aprimorar o sabor de massas e carnes.

Apesar de muito utilizado no Brasil, o orégano é importado principalmente do Chile para suprir as necessidades nacionais. Além disso, informações a respeito de condições ambientais favoráveis ao seu cultivo são poucas, entretanto, pesquisas mostram que a adubação orgânica contribui para a produção de plantas da família Lameaceae, aumentando tanto a massa seca quanto o teor e rendimento do óleo essencial das plantas (Rosal et al., 2011; Bettoni et al., 2014; Luz et al., 2014).

A luz e a fertilidade do solo exercem grande influência na produção vegetal (Seixas et al., 2013), percebe-se a necessidade do uso de alternativas para aumentar a produção destas plantas, em especial do orégano e, assim se beneficiar das condições ambientais favoráveis que o Brasil oferece, especialmente em relação à luminosidade. Neste sentido, técnicas que melhoram a qualidade da luz como o uso de malhas coloridas tem contribuído com o alterações na qualidade de luz do ambiente de cultivo e melhoria na fotossíntese, ocasionando maior eficiência de seu uso (Souza et al., 2011).
Considerando a importância da qualidade e incidência da luz para as plantas e da nutrição mineral destas, o objetivo deste trabalho foi avaliar o efeito do uso de malhas coloridas e adubação orgânica nos índices de trocas gasosas e o crescimento de plantas de orégano.

\section{MATERIAL E MÉTODOS}

\section{Área de estudo}

O experimento foi realizado no campo experimental da Universidade Federal do Recôncavo da Bahia, no município de Cruz das Almas-BA (Brasil) e que está localizado geograficamente a $12^{\circ} 40^{\prime} 19^{\prime \prime} \mathrm{S}$ e $39^{\circ} 06^{\prime} 22^{\prime \prime}$ W e altitude de $225 \mathrm{~m}$.

\section{Delineamento estatístico}

Adotou-se o delineamento inteiramente casualizado, utilizando fatorial $3 \times 4$, sendo dois adubos orgânicos mais o solo como testemunha e quatro ambientes de luz, obtidos com o uso de malhas fotoconversoras nas cores cinza, azul e vermelha e, para a testemunha absoluta, não utilizou sombreamento, tendo incidência de $100 \%$ de luz solar sobre as plantas, com seis repetições.

As plantas de orégano utilizadas (matriz com $60 \mathrm{~d}$ e ciclo de 90 d) foram adquiridas em uma propriedade 
particular no município de Cruz das Almas-BA. As plantas foram cultivadas em recipientes com capacidade para $3 \mathrm{~kg}$, utilizando-se Latossolo Amarelo Álico. A caracterização química do solo e dos adubos utilizados encontram-se na tabela 1 . Utilizou-se o equivalente a $60 \mathrm{t} \mathrm{ha}^{-1}$, para o esterco bovino e o composto orgânico.

\section{Tabela 1. Caracterização química do solo, esterco bovino (EB) e composto orgânico (CO) utilizados no culti- vo das plantas de orégano sob malhas coloridas.}

\begin{tabular}{|c|c|c|c|c|c|c|}
\hline \multirow{2}{*}{ Substrato } & $\mathrm{pH}$ & $\mathrm{P}_{{ }_{\text {Mehlich } 1}}$ & K & $\mathrm{Ca}+\mathrm{Mg}$ & $\mathrm{H}+\mathrm{Al}$ & \multirow{2}{*}{$\frac{M 0}{(\%)}$} \\
\hline & $\left(\mathrm{H}_{2} \mathrm{O}\right)$ & \multicolumn{2}{|c|}{$\mathrm{mg} \mathrm{dm}^{-3}$} & \multicolumn{2}{|c|}{$\mathrm{cmol}_{\mathrm{c}} \mathrm{dm}^{-3}$} & \\
\hline Solo & 6,65 & 18 & 55 & 12,5 & 0 & 2,1 \\
\hline EB & 7,1 & 90 & 780 & 15,6 & 0 & 42,3 \\
\hline $\mathrm{CO}$ & 7,6 & 77 & 470 & 11,5 & 0 & 39 \\
\hline
\end{tabular}

MO: matéria orgânica.

\section{Determinação dos índices de trocas gasosas}

A determinação dos índices de trocas gasosas por meio da mensuração da taxa de assimilação de $\mathrm{CO}_{2}$ $(A)$, transpiração foliar $(E)$, condutância estomática $\left(g_{\mathrm{s}}\right)$ e concentração interna de $\mathrm{CO}_{2}\left(C_{\mathrm{i}}\right)$ foi realizada no terceiro par de folhas, contado a partir do ápice da planta, aos $90 \mathrm{~d}$ após o transplantio. As medidas foram realizadas em $3 \mathrm{~d}$ consecutivos ensolarados entre 8:30 e 11:00 horas da manhã, utilizando-se o analisador portátil de fotossíntese por radiação infravermelha IRGA LCpor+ (ADC, Hoddeston, UK). Por meio da relação da $A / E$ foi determinada a eficiência de uso de água (EUA) pelas plantas.

\section{Análises de crescimento}

No fim do ciclo da cultura, foram avaliadas as características de crescimento por meio de medidas do comprimento da haste principal, diâmetro do caule (DC), número de folhas (NF), área foliar (AF) utilizando-se medidor de área foliar AM 300 e, com a desidratação das plantas em estufa a $65^{\circ} \mathrm{C}$, determinou-se a massa seca total (MST), massa seca da parte aérea (MSPA), massa seca da raiz (MSR) e através da relação $\mathrm{AF} /$ MSF foi obtida a área foliar específica (AFE).

\section{Análises dos dados}

Os dados foram submetidos à análise de variância e as médias foram comparadas pelo teste de Tukey $(P \leq 0,05)$, utilizando-se o programa estatístico SISVAR (Ferreira, 2008).

\section{RESULTADOS E DISCUSSÃO}

Dentre as variáveis analisadas, apenas o número de folhas (NF) e a área foliar (AF) foram influenciadas pela interação da adubação e os ambientes de luz. As demais variáveis de crescimento e trocas gasosas sofreram influência dos fatores isolados; os índices de trocas gasosas foram influenciados apenas pelo ambiente de luz.

Para a interação ambiente de luz e adubos (Tab. 2), o uso de malha azul provocaram o maior o número de folhas (NF), sendo observado aumento de 46\% quando comparadas às plantas cultivadas sob pleno sol e sem adubação. Em plantas de orégano, pesquisadores encontraram resposta linear positiva para o número de folhas em resposta ao aumento de doses de biofertilizante (Bettoni et al., 2014). Plantas que são submetidas a maiores incidências de luz tendem a apresentar menor NF, o que se constatou nesta pesquisa. Podendo ter sido ocasionado pelas prováveis modificações no processo fotossintético (Carvalho et al., 2006), o que resultou, também na menor área foliar obtida.

Em relação à $\mathrm{AF}$, a malha azul e esterco bovino proporcionaram maior valor para esta variável, sendo também constatado aumento da variável nas plantas testemunhas cultivadas sob malha vermelha (Tab. 2). Estes resultados podem ser relacionados a uma estratégia utilizada pelas plantas para maior captação e, assim, aumentarem a eficiência e aproveitamento dos raios de luz.

\begin{tabular}{|c|c|c|c|c|}
\hline \multirow{2}{*}{ Adubo } & \multicolumn{4}{|c|}{ Número de folhas } \\
\hline & Sem malha & Azul & Vermelha & Cinza \\
\hline Testemunha & 1566 cB & $2541 \mathrm{abA}$ & 2939 aA & 1994 bcA \\
\hline EB & $2510 \mathrm{abA}$ & $2900 \mathrm{aA}$ & $2133 \mathrm{abAB}$ & 1744 bA \\
\hline \multirow[t]{3}{*}{ CO } & $1778 \mathrm{abAB}$ & 2483 aA & $1414 \mathrm{bB}$ & $1716 a b A$ \\
\hline & \multicolumn{4}{|c|}{ Área foliar } \\
\hline & Sem malha & Azul & Vermelha & Cinza \\
\hline Testemunha & $33,24 \mathrm{cC}$ & 44,76 bC & $54,76 \mathrm{aB}$ & $30,28 \mathrm{dC}$ \\
\hline EB & $51,26 \mathrm{dA}$ & $58,34 \mathrm{bA}$ & $51,98 \mathrm{cC}$ & $61,18 \mathrm{aA}$ \\
\hline $\mathrm{CO}$ & $37,25 \mathrm{cB}$ & $56,09 \mathrm{bB}$ & 65,53 aA & $33,43 \mathrm{~dB}$ \\
\hline
\end{tabular}

Letras iguais, maiúsculas nas colunas e minúscula nas linhas, não diferem estatisticamente pelo teste de Tukey a $5 \%$ de probabilidade. 
A AF das plantas que estiveram sob as malhas cinza e esterco bovino não diferiu estatisticamente daquelas que permaneceram sob malha vermelha e que receberam como adubo o composto orgânico. Este resultado pode ser devido a malha cinza ser capar de distribuir a luminosidade pela refração direta da luz, não havendo a separação da qualidade desta.

O grau de decomposição dos adubos orgânicos é de extrema importância, já que isso interfere na disponibilização dos nutrientes para as plantas, devido a liberação destes ser influenciada pela mineralização da matéria orgânica (Silva et al., 2012). Além disso, os fertilizantes orgânicos possuem diferentes composições, variando de acordo com sua origem, umidade e processamento (Pereira et al., 2015).

Os resultados para AF encontrados na presente pesquisa corroboram aos encontrados para as plantas de hortelã-japonesa e melissa, em que foi constatado maior AF em plantas crescidas com sombreamento (Chagas et al., 2013; Brant et al., 2009). Isso pode ser devido espécies de Lamiaceae apresentarem maior sensibilidade à intensidade da luz do que à qualidade luminosa.

Para as variáveis de crescimento das plantas, em relação ao ambiente de luz modificada, menor $\mathrm{CH}$ foi detectado nas plantas controle; assim como aquelas que estavam sob a malha cinza, apresentando menores valores para a MSR, MSPA e MST (Tab. 3), observa-se que a cobertura das plantas com malhas coloridas favoreceu o aumento no comprimento da haste, incremento de MSR, MSPA e MST, especialmente onde se utilizou as malhas de cor azul e vermelha. O que pode ter sido ocasionado pela maior área foliar e maior número de folhas, constatados nestas plantas que estavam sombreadas. Resultados semelhantes em plantas de orégano foram obtidos por Corrêa et al. (2010), ao cultivarem as plantas em ambiente modificado com malhas coloridas.

Quando se utiliza a adubação orgânica, é importante considerar o grau de decomposição destes materiais, já que isso interfere na disponibilização dos nutrientes para as plantas, devido a liberação destes ser influenciada pela mineralização da matéria orgânica (Silva et al., 2012). Além disso, os fertilizantes orgânicos possuem diferentes composições, variando de acordo com sua origem, umidade e processamento (Pereira et al., 2015).

Trabalhando com plantas de orégano e adubação orgânica, Murilo-Amador et al. (2015) não observaram diferença estatística para a aplicação do adubo orgânico no comprimento da haste principal das plantas. Por outro lado, em plantas de crajiru (Arrabidaea chica (Bonpl.) B. Verl.), ficou evidente a eficiência do uso de adubo orgânico, aumentando a produção de biomassa aérea, o que os autores atribuíram à maior concentração e disponibilidade de nutrientes ao longo do ciclo da cultura (Brito et al., 2015). Avaliando o efeito de doses de esterco bovino em plantas de melissa Sodré et al. (2013) observaram efeito positivo do esterco na produção de massa seca de folhas e na altura das plantas.

Diferentes espécies vegetais comportam-se de maneiras distintas quando submetidas a diversas condições ambientais, assim como a hortelã-japonesa, onde as plantas cultivadas sem sombreamento acumularam mais MST (Chagas et al., 2013). Por outro lado, M. officinallis (Brant et al., 2009) e guaco (Souza et al., 2011) obtiveram aumento na produção de matéria seca quando crescidas sombreadas. Ao cultivar plantas de alecrim, Souza et al. (2014) obtiveram maior produção de massa seca em plantas cultivadas em pleno sol, comparadas àquelas submetidas ao sombreamento.

As plantas apresentam maior eficiência quando submetidas a ambientes em que a transmissão de luz se dá entre 400 e $700 \mathrm{~nm}$, sendo este comprimento o mais adequado para a fotossíntese (Taiz e Zeiger, 2009), assim, quando cultivadas sob malha azul apresentam melhor comportamento, isso porque a malha azul transmite luz abrangendo de 470 a 750 (Oren-Shamir et al., 2001), Além disso, ao incidir sobre o vegetal, a luz proporciona várias respostas, como influência em padrões de processos fisiológicos como no crescimento e desenvolvimento da planta, sendo estas respostas diferentes para cada espécie vegetal.

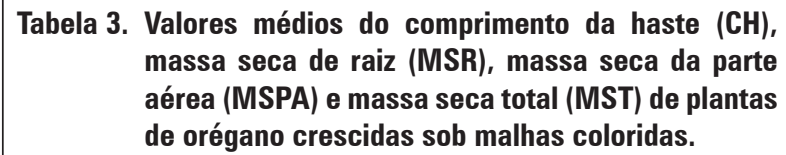

\begin{tabular}{|l|c|c|c|c|}
\hline \multicolumn{1}{|c|}{ Malha } & CH & MSR & MSPA & MST \\
\hline Sem malha & $11,18 \mathrm{~b}$ & $30,97 \mathrm{~b}$ & $17,55 \mathrm{~b}$ & $48,52 \mathrm{~b}$ \\
\hline Azul & $30,12 \mathrm{a}$ & $64,60 \mathrm{a}$ & $26,01 \mathrm{a}$ & $90,61 \mathrm{a}$ \\
\hline Vermelha & $27,87 \mathrm{a}$ & $57,77 \mathrm{a}$ & $22,13 \mathrm{a}$ & $79,90 \mathrm{a}$ \\
\hline Cinza & $22,67 \mathrm{a}$ & $33,62 \mathrm{~b}$ & $17,01 \mathrm{~b}$ & $50,63 \mathrm{~b}$ \\
\hline
\end{tabular}

Letras iguais na coluna não diferem estatisticamente pelo teste de Tukey a 5\% de probabilidade. 
Em pesquisa realizada com a cultura do orégano em ambiente protegido e adubação orgânica, foi constatado que as plantas sombreadas aumentaram a produção de massa seca e fresca em 118 e 165\%, respectivamente (Murilo-Amador et al., 2015). Desta forma os autores sugeriram que o sombreamento para a cultura do orégano apresenta-se como beneficiadora para aumento na produção das plantas.

$\mathrm{O}$ uso do esterco bovino aumentou o $\mathrm{CH}$ das plantas, assim como a MSR, MSPA e MST (Tab. 4). A área foliar específica apresentou o maior valor nas plantas adubadas com composto orgânico, diferindo estatisticamente dos valores encontrados para as plantas adubadas com o esterco bovino e as que não receberam adubação, mostrando a importância da presença da matéria orgânica no crescimento das plantas. Isso porque, a maioria dos adubos orgânicos fornece os nutrientes às plantas e proporciona melhoria nas propriedades físicas, químicas e biológicas do solo (Pinto et al., 2001).

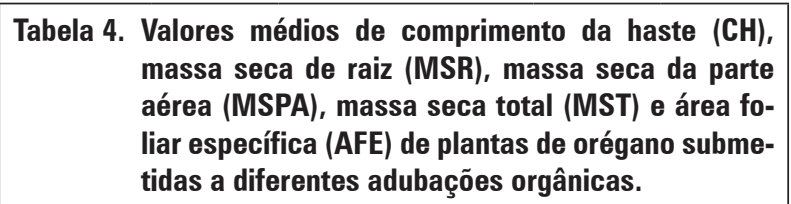

\begin{tabular}{|l|c|c|c|c|c|}
\hline \multicolumn{1}{|c|}{ Adubo } & \multicolumn{1}{c|}{ CH } & \multicolumn{1}{c|}{ MSR } & MSPA & MST & \multicolumn{1}{c|}{ AFE } \\
\hline Testemunha & $19,43 \mathrm{~b}$ & $37,57 \mathrm{~b}$ & $19,72 \mathrm{~b}$ & $57,29 \mathrm{~b}$ & $5,69 \mathrm{~b}$ \\
\hline EB & $28,42 \mathrm{a}$ & $58,59 \mathrm{a}$ & $24,60 \mathrm{a}$ & $83,19 \mathrm{a}$ & $5,82 \mathrm{~b}$ \\
\hline C0 & $21,03 \mathrm{~b}$ & $44,07 \mathrm{ab}$ & $17,71 \mathrm{~b}$ & $61,78 \mathrm{~b}$ & $9,07 \mathrm{a}$ \\
\hline
\end{tabular}

Letras iguais na coluna não diferem estatisticamente pelo teste de Tukey a $5 \%$ de probabilidade.

Quando se utiliza a adubação orgânica, é importante considerar o grau de decomposição destes materiais, já que isso interfere na disponibilização dos nutrientes para as plantas, devido a liberação destes ser influenciada pela mineralização da matéria orgânica (Silva et al., 2012). Além disso, os fertilizantes orgânicos possuem diferentes composições, variando de acordo com sua origem, umidade e processamento (Pereira et al., 2015).

Trabalhando com plantas de orégano e adubação orgânica, Murilo-Amador et al. (2015) não observaram diferença estatística para a aplicação do adubo orgânico no comprimento da haste principal das plantas. Por outro lado, em plantas de crajiru (Arrabidaea chica (Bonpl.) B. Verl.), ficou evidente a eficiência do uso de adubo orgânico, aumentando a produção de biomassa aérea, o que os autores atribuíram à maior concentração e disponibilidade de nutrientes ao longo do ciclo da cultura (Brito et al., 2015). Avaliando o efeito de doses de esterco bovino em plantas de melissa Sodré et al. (2013) observaram efeito positivo do esterco na produção de massa seca de folhas e na altura das plantas.

As trocas gasosas foram influenciadas apenas pela modificação do ambiente de cultivo pelo uso de maIhas coloridas. Em relação aos índices de trocas gasosas, plantas sombreadas obtiveram menor valor para a taxa assimilatória (Tab. 5). O mesmo aconteceu com a transpiração foliar e condutância estomática, ambas apresentando maiores valores nas plantas cultivadas a pleno sol.

O fato de plantas sombreadas apresentarem menores valores de taxa de assimilação líquida pode ser justificado devido à pouca irradiância e à baixa temperatura influenciadas pela sazonalidade, o que resulta na redução das taxas fotossintéticas (Schock et al., 2014). Além disso, a eficiência fisiológica das plantas quando submetidas às diferentes condições ambientais varia conforme as espécies. Assim como comprovaram Coelho et al. (2014) em plantas de feijão, quando submetidas a diferentes sombreamentos. Comprovando

Tabela 5. Valores médios para a transpiração foliar $(E)$, condutância estomática $\left(g_{\mathrm{s}}\right)$, taxa de assimilação líquida $(A)$, concentração interna de carbono $\left(C_{i}\right)$ e eficiência do uso de água $(W U E)$ em plantas de orégano cultivadas sob ambientes de luz modificada.

\begin{tabular}{|c|c|c|c|c|c|}
\hline Ambiente de luz & $\begin{array}{c}E \\
\left(\mathrm{mmol} \mathrm{H}_{2} \mathrm{O} \mathrm{m}^{-2} \mathrm{~s}^{-1}\right)\end{array}$ & $\begin{array}{c}g_{\mathrm{s}} \\
\left(\mathrm{mol} \mathrm{m}^{-2} \mathrm{~s}^{-1}\right)\end{array}$ & $\frac{A}{\left(\mu \mathrm{mol} \mathrm{CO}_{2} \mathrm{~m}^{-2} \mathrm{~s}^{-1}\right)}$ & $\begin{array}{c}C_{i} \\
\left(\mathrm{mmol} \mathrm{m}^{-2} \mathrm{~s}^{-1}\right)\end{array}$ & $\begin{array}{c}\text { WUE } \\
\left(\mathrm{mmol} \mathrm{CO}_{2} \mathrm{~mol}^{-1} \mathrm{H}_{2} \mathrm{O}\right)\end{array}$ \\
\hline Sem malha & $6,11 \mathrm{a}$ & $1,04 \mathrm{a}$ & $15,61 \mathrm{a}$ & $340,50 \mathrm{a}$ & $2,56 \mathrm{a}$ \\
\hline Malha cinza & $4,31 \mathrm{~b}$ & $0,13 \mathrm{~b}$ & $6,97 \mathrm{~b}$ & $283,60 \mathrm{~b}$ & $1,62 b$ \\
\hline Malha vermelha & $2,35 c$ & $0,18 b$ & $6,44 b$ & 337,17 a & $2,75 a$ \\
\hline Malha azul & $5,13 b$ & $0,21 \mathrm{~b}$ & $8,75 b$ & $311,83 a b$ & $1,71 \mathrm{~b}$ \\
\hline CV (\%) & 13,54 & 15,01 & 14,09 & 19,99 & 12,75 \\
\hline
\end{tabular}

Letras iguais na coluna não diferem estatisticamente pelo teste de Tukey a $5 \%$ de probabilidade. 
que, quando não estavam expostas ao sol houve aumento de 19\% na taxa fotossintética, o que resultou em maior produção de massa seca das plantas. Isso pode ser explicado devido as plantas quando encontram-se adaptadas a algum ambiente, como no caso às condições de luminosidade, estas acumulam fotoassimilados nas folhas, o que resulta em sua expansão e, consequentemente, maior eficiência fisiológica (Garcez Neto et al., 2010). Segundo Gomes et al. (2008), o aumento da radiação sobre as plantas incrementa as taxas fotossintéticas.

Em relação à $E U A$, maior eficiência foi detectada em plantas testemunha e as cultivadas sob malha vermelha. O que pode estar ligado ao fato de estas terem sofrido algum processo de estresse, já que, quando as plantas passam por algum estresse podem reduzir ou limitar a condutância estomática e a transpiração e aumentam a eficiência do usoda água (Dalastra et al., 2014). Este fato ficou evidente nas plantas cultivadas sob malha vermelha, apresentando baixos valores para a condutância estomática e taxa transpiratória e aumento na eficiência do uso da água.

A menor variação da umidade do ar podem ocasionar menor transpiração foliar nas plantas, já que, em ambientes protegidos ou parcialmente protegidos, há menor variação da umidade relativa do ar (Souza et al., 2011). Isto porque ambientes protegidos contribuem com o desenvolvimento dos vegetais, através do sinergismo entre radiação solar, temperatura e umidade do ar. Criando, desta maneira, um ambiente protegido de possíveis efeitos meteorológicos que afetam as plantas. Entretanto, os maiores valores de transpiração podem promover aumento na resistência da entrada de $\mathrm{CO}_{2}$ pelos estômatos, modificando a relação da taxa assimilatória líquida e concentração de $\mathrm{CO}_{2}$. De acordo com Medina et al. (1999), em condições naturais a temperatura e a umidade relativa do ar são inversamente proporcionais e a resposta do metabolismo vegetal é o resultado da interação destes fatores ambientais.

Temperatura mais elevada ocasiona aumento na radiação sobre as folhas, resultando em maior diferença de vapor entre a folha e o ar, aumentando a transpiração e elevando-se a taxa transpiratória (Luttge, 1997), o que foi constatado nas plantas controle (Tab. 5). Plantas de orégano que não sombreadas apresentaram maior condutância estomática, isso pode ser justificado devido estas ao estarem em ambientes com pouca água, além de reduzir a abertura estomática, também diminui o tempo de abertura dos estômatos (Santos et al., 2014), isso porque a gs está ligada à abertura estomática (Silveira et al., 2013). Assim, mudanças na resistência estomática podem acarretar a regulação da perda de água e controle da taxa de absorção de $\mathrm{CO}_{2}$ que são necessárias no período da fotossíntese (Taiz e Zeiger, 2009). Fatores ambientais e intrínseco das plantas podem influenciar a condutância estomática (England e Attiwill, 2011).

A maior concentração interna de $\mathrm{CO}_{2}$ foi constatada nas plantas cultivadas sob pleno sol e sob a malha vermelha (Tab. 5), o que está diretamente relacionado à taxa assimilatória líquida do $\mathrm{CO}_{2}$, que pode ser ocasionado por modificações no ambiente de cultivo (como no caso, a modificação na luz do ambiente pelo uso das malhas coloridas), conforme explicam (Taiz e Zeiger, 2009).

Ao se avaliar as trocas gasosas em plantas de melão, detectou-se menores valores quando as plantas permaneceram com dois frutos e não causou queda na assimilação líquida de $\mathrm{CO}_{2}$, fato este que os autores relacionaram com a circunstância das plantas não terem sofrido estresse (Dalastra et al., 2014). O que também pode justificar os resultados encontrados para as plantas de orégano. As malhas coloridas podem modificar a radiação interna e reduzir intensamente a temperatura e umidade do ar, bem como a radiação fotossinteticamente ativa.

A modificação da cor e qualidade da luz podem ocasionar respostas nas plantas, uma vez que a luz é o fator principal pelas reações químicas e fisiológicas das plantas e, havendo mudanças no espectro da luz pode promover aumento no rendimento das culturas (Matheny, 1992).

Por meio dos resultados obtidos no presente estudo, bem como pelos trabalhos já realizados com cultivo de plantas em ambientes modificados pelo uso de malhas coloridas, bem como pelo uso de adubos orgânicos, pode-se dizer que o uso da adubação orgânica e de malhas coloridas apresentam-se como fortes aliados do produtor de plantas aromáticas. Confirmando assim, a hipótese que a adubação orgânica contribui com o crescimento de plantas e que a modificação da luz incidente nos vegetais exerce grande influência no crescimento de plantas, especialmente de orégano.

\section{CONCLUSÕES}

Plantas crescidas sob malha nas cores azul e vermelha e adubação orgânica aumentam a produção de massa seca. 
Malhas coloridas e o uso da adubação orgânica proporcionam aumento na área foliar e número de folhas de plantas de orégano.

Os índices de trocas gasosas apresentam diferenças significativas em função do ambiente de cultivos. Plantas sombreadas apresentam menor taxa assimilatória líquida, condutância estomática, concentração interna de carbono e transpiração foliar. No entanto, ao serem submetidas a algum estresse, estas proporcionam maior eficiência no uso da água.

\section{AGRADECIMENTOS}

À Coordenação de Aperfeiçoamento de Pessoal de Nível Superior (Capes); Conselho Nacional de Desenvolvimento Científico e Tecnológico $(\mathrm{CNPq})$ e à Fundação de Amparo à Pesquisa do Estado da Bahia (FAPESB) pelo apoio financeiro e concessão de bolsa de estudo.

Conflito de interesses: o manuscrito foi preparado e revisado com a participação de todos os autores, que declaram não ter qualquer conflito de interesses que possa afetar a validade dos resultados do trabalho apresentado.

\section{REFERÊNCIAS BIBLIOGRÁFICAS}

Bettoni, M.B., E.G.S. Fabrin, M. Procopiuk e A.F. Mógor. 2014. Crescimento de mudas de orégano submetidas a doses e frequências de aplicação de Ácido L-glutâmico em sistema orgânico. Rev. Bras. Plantas Med. 16(1), 83-88. Doi: 10.1590/S1516-05722014000100012

Brant, R.S., J.E.B.O. Pinto, L.F. Rosal, C.J.B. Albuquerque, P.J. Ferri e R.M. Corrêa. 2009. Crescimento, teor e composição do óleo essencial de melissa cultivada sob malhas fotoconversoras. Ciênc. Rural 39(5), 14011407. Doi: 10.1590/S0103-84782009005000083

Brito, A.U., F.C.M. Chaves, J.M. Oka, M.M.B. Azevedo e A.C. Batista. 2015. Produção de biomassa aérea, teor e rendimento de extrato das folhas de crajiru (Arrabidaea chica (Bonpl.) B. Verl.) em função de adubação orgânica em Manaus, estado do Amazonas, Rev. Bras. Plantas Med. 17(3), 444-453. Doi: 10.1590/1983084X/12_123

Carvalho, N.O.S., C.R. Pelacani, M.O.S. Rodrigues e I.C. Crepaldi. 2006. Crescimento inicial de plantas de licuri (Syagrus coronata (Mart.) Becc.) em diferentes níveis de luminosidade. Rev. Árvore 30(3), 351-357. Doi: 10.1590/S0100-67622006000300005

Chagas, J.H., J.E.B.O. Pinto, S.K.V. Bertolucci, A.G. Costa, H.C.R. Jesus e P.B. Alves. 2013.
Produção, teor e composição química do óleo essencial de hortelã-japonesa cultivada sob malhas fotoconversoras. Hortic. Bras. 31(2), 297-303. Doi: 10.1590/S0102-05362013000200020

Coelho, D.S., M.A.D. Marques, J.A.B. Silva, M.S. Garrido e P.G.S. Carvalho. 2014. Respostas fisiológicas em variedades de feijão caupi submetidas a diferentes níveis de sombreamento. R. Bras. Bioci. 12(1), 14-19.

Corrêa, R.M., J.E.B.P. Pinto, E.S. Reis, L.C.B. Costa, P.B. Alves, E.S. Niculan e R.S. Brant. 2010. Adubação orgânica na produção de biomassa de plantas, teor e qualidade de óleo essencial de orégano (Origanum vulgare L.) em cultivo protegido. Rev. Bras. Plantas Med. 12(1), 80-89. Doi: 10.1590/S1516-05722010000100012

Dalastra, G.M., M.M. Echer, V.F. Guimarães, T.L. Hacmann e A.M. Inagaki. 2014. Trocas gasosas e produtividade de três cultivares de meloeiro conduzidas com um e dois frutos por planta. Bragantia 73(4), 365-371. Doi: 10.1590/1678-4499.206

England, J.R. e P.M. Attiwill. 2011. Changes in stomatal frequency, stomatal conductance and cuticle thickness during leaf expansion in the broad-leaved evergreen species, Eucalyptus regnans. Trees 25(987). Doi: 10.1007/s00468-011-0573-7

Ferreira, D.F. 2008. SISVAR: um programa para análises estatísticas e ensino de estatística. Rev. Cient. Symposium 6(1), 36-41.

Garcez Neto, A.F., R. Garcia, D.J. Moot e K.F. Gobbi. 2010. Aclimatação morfológica de forrageiras temperadas a padrões e níveis de sombreamento. R. Bras. de Zootec. 339(1),42-50.Doi:10.1590/S1516-35982010000100006

Gomes, I.A.C., E.M. Castro, A.M. Soares, J.D. Alves, M.I.N. Alvarenga, E. Alves, J.P.R.A.D. Barbosa e D.D. Fries. 2008. Alterações morfofisiológicas em folhas de Coffea arabica L. cv. Oeiras sob influência do sombreamento por Acacia mangium Willd. Ciênc. Rural 38(1), 109115. Doi: 10.1590/S0103-84782008000100018

Luttge, U. 1997. Interaction of stress factors and the midday depression in plants with C3: photosynthesis. Physio. Ecol. Trop. Plants 35(1), 122-124.

Luz, J.M.O., R.F. Resende, S.M. Silva, D.G. Santana, J.S. Camilo, A.F. Blank e L.L. Haber. 2014. Produção de óleo essencial de Ocimum basilicum L. em diferentes épocas, sistemas de cultivo e adubações. Bol. Latinoam. Caribe Plantas Med. Arom. 13(1), 69-80.

Matheny, T.A., P.G. Hunt e M.J. Kasperbauer. 1992. Potato tuber productions in response to reflected light from different colored mulches. Crop Sci. 32(1), 1021-1024. Doi: 10.2135/cropsci1992.0011183X003200040037x

Medina, C.L., E.C. Machado e M.M.A. Gomes. 1999. Condutância estomática, transpiração e fotossíntese em laranjeira 'Valência' sob deficiência hídrica. Braz. J. Plant Physiol. 11(1), 29-34. 
Morelli, G. e I. Ruberti. 2000. Shade avoidance responses. Driving auxin along lateral routes. Plant Physiol. 122(1), 621-626. Doi: 10.1104/pp.122.3.621

Murilo-Amador, B., L.E. Morales-Prado, E. Troyo-Diéguez, M.V. Córdoba-Matson, L.G. Hernández-Montiel, E.O. Rueda-Puente e A. Nieto-Garibay. 2015. Changing environmental conditions and applying organic fertilizers in Origanum vulgare L. Front. Plant Sci. 6(549), 1-15. Doi: 10.3389/fpls.2015.00549

Oren-Shamir, M., E.E. Gussakovsky, E. Shpiegel, A. Nissim-Levi, K. Ratner, R. Ovadia, e Y.E. Giller. 2001. Coloured shade nets can improve the yield and quality of green decorative branches of Pittosporum variegatum. J. Hort. Sci. Biotech. 76(3), 353-361. Doi: 10.1080/14620316.2001.11511377

Pereira, L.B., O. Arf, N.C.B. Santos, A.E.Z. Oliveira e L.K. Komuro. 2015. Manejo da adubação na cultura do feijão em sistema de produção orgânico. Pesq. Agropec. Trop. 45(1), 29-38. Doi: 10.1590/1983-40632015v4528018

Pinto, J.E.B.P., N.E.A. Castro, S.K.V. Bertolucci e R.C. Pinheiro. 2001. Cultivo e produção de plantas medicinais, aromáticas e condimentares. FAEPE, Lavras-MG, Brasil.

Rosal, L.F., J.E.B.P. Pinto, S.K.V. Bertolucci, R.S. Brant, E.S. Niculau e P.B. Alves. 2011. Produção vegetal e de óleo essencial de boldo pequeno em função de fontes de adubos orgânicos. Rev. Ceres 58(5), 670-678. Doi: 10.1590/S0034-737X2011000500020

Sales, J.F., J.E.B.P. Pinto, P.H. Ferri, F.G. Silva, C.B.A. Oliveira e P.P. Botrel. 2009. Influência do nível de irradiância no crescimento, produção e composição química do óleo essencial de hortelã-do-campo (Hyptis marrubioides Epl.). Semina Ciênc. Agr. 30, 79-386. Doi: 10.5433/1679-0359.2009v30n2p389

Santos, L.M., E.C. Silva e C.D. Silva Júnior. 2014. Análise preliminar das trocas gasosas, fluorescência da clorofila e potencial hídrico de plantas de juazeiro em uma região semi-árida de Sergipe, Brasil. Scientia Plena $10(2), 1-10$

Schock, A.A., A. Ramm, E.G. Martinazzo, D.M. Silva e M.A. Bacarin. 2014. Crescimento e fotossíntese de plantas de pinhão-manso cultivadas em diferentes condições de luminosidade. R. Bras. Eng. Agríc. Ambiental 18(1), 3-9.

Seixas, P.T.L., H.G. Castro, D.P. Cardoso, A.F. Chagas Júnior, I.R. Nascimento e L.C.A. Barbosa. 2013. Efeito da adubação mineral na produção de biomassa e no teor e composição do óleo essencial do capim-citronela. Biosci. J. 29(4), 852-858.

Silva, J.A., A.P. Oliveira, G.S. Alves, L.F. Cavalcante, A.N.P. Oliveira e M.A.M. Araújo. 2012. Rendimento do inhame adubado com esterco bovino e biofertilizante no solo e na folha. R. Bras. Eng. Agríc. Ambiental 16(3), 253-257.

Silveira, H.M., E.A. Ferreira, D.V. Silva, M.D. Castro Neto, F.P. Carvalho, J.B. Santos e A.A. Silva. 2013. Características fisiológicas de cultivares de mandioca após aplicação do mesotrione. Planta Daninha 31(2), 403-409. Doi: 10.1590/S0100-83582013000200018

Sodré, A.C.B., L.L. Haber, J.M.Q. Luz, M.O.M. Marques, e C.R. Rodrigues. 2013. Adubação orgânica e mineral em melissa. Hortic. Bras. 31(1), 147-152. Doi: 10.1590/S0102-05362013000100023

Souza, G.S., E.M. Castro, A.M. Soares, A.R. Santos y E. Alves. 2011. Teores de pigmentos fotossintéticos, taxa de fotossíntese e estrutura de cloroplastos de plantas jovens de Mikanialae vigata Schultz Bip. ex Baker cultivadas sob malhas coloridas. Semina Ciênc. Agr. 32(Supl. 1), 1843-1854. Doi: 10.5433/1679-0359.2016v37n6p3903

Souza, G.S., J.S. Silva, U.C. Oliveira, R.B. Santos Neto e A.R. Santos. 2014. Crescimento vegetativo e produção de óleo essencial de plantas de alecrim cultivadas sob telas coloridas. Biosci. J. 30(Suppl. 1), 232-239.

Taiz, L. e E. Zeiger. 2009. Fisiologia vegetal. $4^{\text {th }}$ ed. Artmed, Porto Alegre-RS, Brasil. 